\title{
Antibiosis mechanism of resistance to spotted stem borer, Chilo partellus in sorghum, Sorghum bioclor
}

\author{
V. Kishore Kumar ${ }^{\mathrm{a}, \mathrm{b}}$, H.C. Sharma ${ }^{\mathrm{a}, *}$, K. Dharma Reddy ${ }^{\mathrm{b}}$ \\ ${ }^{a}$ International Crops Research Institute for the Semi-Arid Tropics (ICRSAT), Patancheru 502 324, Andhra Pradesh, India \\ ${ }^{\mathrm{b}}$ ANGR Agricultural University, Rajendranagar, Hyderabad 500 030, Andhra Pradesh, India
}

Received 6 January 2005; accepted 4 April 2005

\begin{abstract}
Spotted stem borer, Chilo partellus (Swinhoe), is the most important pest of sorghum in Asia and South and Eastern Africa, and host plant resistance is an important component for controlling this pest under subsistence farming conditions. Therefore, we studied the antibiosis mechanism of resistance in a diverse array of 20 sorghum genotypes at the seedling stage by incorporating the freeze-dried leaf powder into artificial diet. Freeze-dried sorghum leaf powder at $12.5 \mathrm{~g}$ per $250 \mathrm{ml}$ of the standard artificial diet or replacement of chickpea flour in the artificial diet by $50 \%$ with sorghum leaf powder can be used to quantify the extent of antibiosis mechanism of resistance to $C$. partellus in sorghum. There was a significant variation in larval survival, larval and pupal weights, larval and pupal periods, and percentage pupation and adult emergence in diets impregnated with freeze-dried leaf powder of different sorghum genotypes. Sorghum genotypes such as IS 1044, IS 2123, IS 1054, IS 18573, and ICSV 714 showed antibiosis to $C$. partellus in terms of reduced survival and development. Principal component analysis indicated that there is considerable diversity in sorghum genotypes for antibiosis to $C$. partellus. Genotypes placed in different groups can be used in resistance breeding programs to diversify the basis of resistance to this pest.

(C) 2005 Elsevier Ltd. All rights reserved.
\end{abstract}

Keywords: Sorghum; Stem borer; Chilo partellus; Plant resistance; Resistance mechanism; Antibiosis

\section{Introduction}

Sorghum is one of the major cereal crops in the semiarid tropics (SAT). Grain yields of sorghum on peasant farms are generally low $\left(500-800 \mathrm{~kg} \mathrm{ha}^{-1}\right)$, and one of the major factors limiting sorghum yields are insect pests. Sorghum is damaged by over 150 insect species from sowing to the crop harvest, of which sorghum shoot fly (Atherigona soccata Rondani), spotted stem borer (Chilo partellus Swinhoe), sorghum midge (Stenodiplosis sorghicola Coquillett), and head bugs (Calocoris angustatus Lethiery and Eurystylus oldi Poppius) are most important worldwide (Sharma, 1993). Several species of stem borers attack sorghum in different

\footnotetext{
${ }^{*}$ Corresponding author. Tel.: + 914030713314 .

E-mail address: h.sharma@cgiar.org (H.C. Sharma).
}

sorghum-growing regions (Nwanze, 1997), of which the spotted stem borer, C. partellus is predominant in Asia and eastern and southern Africa. Stem borers cause an estimated loss of US \$266 million annually (ICRISAT, 1992). The spotted stem borer, C. partellus attacks sorghum plants from two weeks after germination until crop harvest. The young larvae feed on leaf whorl leaves at the seedling stage, while the older larvae leave the whorl and bore into the stem where they damage the growing point and cause a characteristic "deadheart" symptom. In older plants, the larvae feed inside the stem causing extensive tunneling, which may cause lodging and interfere with nutrient supply to the developing grains. Insecticide application for stem borer control is uneconomic under subsistence farming, and is largely beyond the means of resource poor farmers. Therefore, host plant resistance (HPR) assumes a pivotal role in 
controlling stem borer damage either alone or in combination with other methods of control.

Systematic screening of the world germplasm collection for resistance to spotted stem borer has been undertaken in the Indian national sorghum improvement program (Singh et al., 1968; Pradhan, 1971; Jotwani, 1978) and at the International Crops Research Institute for the Semi-Arid Tropics (ICRISAT), and over 30,000 germplasm accessions have been screened for resistance (Taneja and Leuschner, 1985; Sharma et al., 1992, 2003). Amongst the identified sources, a number of mechanisms contribute to sorghum resistance to the stem borer, including non-preference for oviposition, reduced feeding by the first-instars on young leaves, low deadheart formation, reduced tunneling, and tolerance to leaf damage and stem tunneling (Chapman et al., 1983; Dabrowski and Kidiavai, 1983; Woodhead and Taneja, 1987; Sharma and Nwanze, 1997). Knowledge of the resistance mechanisms and associated factors is essential for effective utilization of resistant sources in the crop improvement programs. However, because of large genotype $\times$ environment interactions, it becomes difficult to quantify different mechanisms of resistance under field conditions. Therefore, we studied the antibiosis mechanism of resistance to $C$. partellus in a diverse array of stem borer-resistant and -susceptible sorghum genotypes by impregnating the freeze-dried leaf powder into artificial diet under laboratory conditions.

\section{Material and methods}

The survival and development of C. partellus was studied on artificial diet (Sharma et al., 1992), impregnated with freeze-dried leaf powder of a diverse array of 20 sorghum genotypes. The test material consisted of 11 germplasm accessions showing resistance to stem borer under field conditions (IS 1044, IS 1054, IS 2123, IS 2263, IS 2269, IS 5469, IS 5566, IS 12308, IS 13100, IS 18333, and IS 18573) (Sharma et al., 1992, 2003), two improved stem borer-resistant lines developed at ICRISAT (ICSV 705 and ICSV 714), three landraces from Africa (S 21444 - a guinense sorghum from West Africa, Seredo - a red grain variety from East Africa, and Naga White - a chalky grain sorghum variety from Ghana), and two commercially released cultivars from India (ICSV 1 and ICSV 112). This represented a diverse array of stem borer-resistant and borer-susceptible material from different regions/races of sorghum.

The sorghum seedlings were grown under greenhouse conditions during the postrainy season (December 1998 to March 1999) at the ICRISAT, Patancheru, Andhra Pradesh, India. The plants were raised on medium sized pots $(60 \mathrm{~cm}$ dia, $30 \mathrm{~cm}$ deep) in the greenhouse at ambient atmospheric conditions $\left(30 \pm 5{ }^{\circ} \mathrm{C}, 65 \pm 5 \%\right.$
$\mathrm{RH}$, and $12 \mathrm{~h}$ photoperiod). The potting mixture consisted of red soil and farmyard manure (2:1). Before sowing, diammonium phosphate was applied at $50 \mathrm{~g}$ per pot, and 10 seeds were sown in each pot. At 10 days after seedling emergence, three healthy seedlings were retained in each pot. Urea at $10 \mathrm{~g}$ per pot was applied after thinning. The plants were watered as and when needed. Antibiosis to $C$. partellus in different sorghum genotypes was studied by incorporating lyophilized leaf powder into the artificial diet. For this purpose, leaves of the test genotypes were collected from 25-day-old plants raised under greenhouse conditions. Two to three whorl leaves were removed with scissors at the growing point from each plant (on which the larvae feed under natural conditions). The leaves were washed and then freeze dried for $36 \mathrm{~h}$ in a lyophilizer $\left(-50^{\circ} \mathrm{C}\right)$ to avoid changes in chemical composition of the leaves. The dried up leaves were powdered in a Willey mill to 80 mesh size for use in the artificial diet.

\subsection{Effect of different amounts of sorghum leaf powder on survival and development of Chilo partellus}

To obtain an idea of the optimum amount of sorghum leaf powder needed in the artificial diet to measure antibiosis to $C$. partellus, experiments were conducted on the effect of different amounts of leaf powder in the artificial diet on survival and development, and the effect of different proportions of chickpea flour and sorghum leaf powder in the artificial diet on survival and development of $C$. partellus. For studying the effect of different amounts of sorghum leaf powder in the artificial diet on survival and development of $C$. partellus; $0,7.5,12.5,17.5$, and $22.5 \mathrm{~g}$ of sorghum leaf powder of sorghum hybrid CSH 1 was added in $250 \mathrm{ml}$ of standard artificial diet used for rearing C. partellus (Sharma et al., 1992) (Table 1). Sorghum leaf powder was soaked in $100 \mathrm{ml}$ warm water $\left(70^{\circ} \mathrm{C}\right)$, and blended with Fraction A ingredients for 2 min. Agar-agar was boiled in $80 \mathrm{ml}$ water (Fraction B), cooled to $40^{\circ} \mathrm{C}$, and then poured into the blender containing the Fraction A. Formaldehyde was added finally and all constituents blended for $3 \mathrm{~min}$. The diet thus prepared was poured in to plastic cups of $50 \mathrm{ml}$ capacity. Each cup had $20 \mathrm{ml}$ diet. The diet was allowed to settle for $4 \mathrm{~h}$. Ten firstinstar larvae were released into each cup. There were five replications in a completely randomized design. At 10 days after infestation, data were recorded on larval survival and larval weight.

In another experiment, leaf powder from three sorghum genotypes (IS 5469-a germplasm line with high levels of resistance to stem borer, ICSV 705-an improved line with moderate levels of resistance to stem borer, and ICSV 745-an improved variety highly susceptible to stem borer under field conditions) was impregnated into the artificial diet. For each genotype, 
Table 1

Artificial diet used for rearing spotted stem borer, Chilo partellus in the laboratory

\begin{tabular}{lc}
\hline Ingredient & Quantity \\
\hline Fraction $A$ & \\
Water & $80.00 \mathrm{ml}$ \\
Chickpea flour & $12.00 \mathrm{~g}$ \\
Brewers yeast & $1.28 \mathrm{~g}$ \\
Sorbic acid & $0.16 \mathrm{~g}$ \\
Vitamin E (Viteolin capsules) & $0.18 \mathrm{~g}$ \\
Methyl parahydroxy benzoate & $0.26 \mathrm{~g}$ \\
Ascorbic acid & $0.42 \mathrm{~g}$ \\
Sorghum leaf powder & $12.00 \mathrm{~g}$ \\
& \\
Fraction B & $1.64 \mathrm{~g}$ \\
Agar-agar & $65.00 \mathrm{ml}$ \\
Water & $0.13 \mathrm{ml}$ \\
Formaldehyde & \\
\end{tabular}

there were five treatments with different proportions of chickpea flour and sorghum leaf powder (0:6, 2:4, 3:3, 4:2, and 5:1 — chickpea flour:sorghum leaf powder). The diet was prepared as described above. There were five replications for each treatment in a completely randomized design. Ten first-instar larvae were released into each cup. Ten days after infestation, data were recorded on larval survival and larval weight.

\subsection{Survival and development of Chilo partellus on artificial diet impregnated with lyophilized leaf powder of different sorghum genotypes}

Antibiosis component of resistance to C. partellus in 20 sorghum genotypes was assessed by impregnating a 1:1 proportion of chickpea flour:sorghum leaf powder in a standard artificial diet (based on the results obtained above). There were three replications for each genotype in a completely randomized design. Diet was poured into $250 \mathrm{ml}$ capacity plastic cups and each cup had $150 \mathrm{ml}$ diet. Larval survival and larval weight were recorded at 10 days after releasing the larvae. After pouring the diet into the cups, it was allowed to cool for $2-3 \mathrm{~h}$ on the laboratory table. Ten first-instar larvae were released into each cup, using a fine camel hairbrush. The cups were kept in the rearing room in the dark for three days (because the first-instar larvae have a strong photosensitive behavior, and settle better on the diet in darkness). In the rearing room, temperature was maintained at $28 \pm 1{ }^{\circ} \mathrm{C}, 60-70 \% \mathrm{RH}$, and $12 \mathrm{~h}$ photoperiod. Observations were recorded on larval survival and larval weight at 10 days after releasing the larvae into the artificial diet, pupation and adult emergence. Pupal weight was recorded for each sex separately on the second day after pupation. The pupae were sexed on the basis of their relative size and genital openings (Sithanantham and Subramaniam,
1975). Percentage pupation and adult emergence were calculated in relation to the total number of larvae released in to each cup.

Data on percentage larval survival at 10 days after initiating the experiment, and larval weight were subjected to angular and square root transformation before analysis of variance. Data were subjected to analysis of variance using GENSTAT release 5.0. The significance of differences between the treatments was measured by $F$-test at $P 0.05$, while the treatment means were compared using the least significant difference (LSD) at $P$ 0.05. Data on larval survival, larval and pupal weight, percentage pupation and adult emergence, and duration of post-embryonic development was subjected to principal component analysis to assess the genotypic diversity for resistance to spotted stem borer, C. partellus.

\section{Results}

\subsection{Effect of different amounts of sorghum leaf powder on survival and development of $C$. partellus}

Larval survival ranged from $72 \%$ in artificial diet without sorghum leaf powder and the diet having $22.5 \mathrm{~g}$ of freeze-dried sorghum leaf powder (per $250 \mathrm{ml}$ artificial diet) to $86 \%$ in the diet having $12.5 \mathrm{~g}$ sorghum leaf powder (Fig. 1). Larval weight was lowest in larvae reared on artificial diet without sorghum leaf powder, while maximum larval weight was recorded in larvae
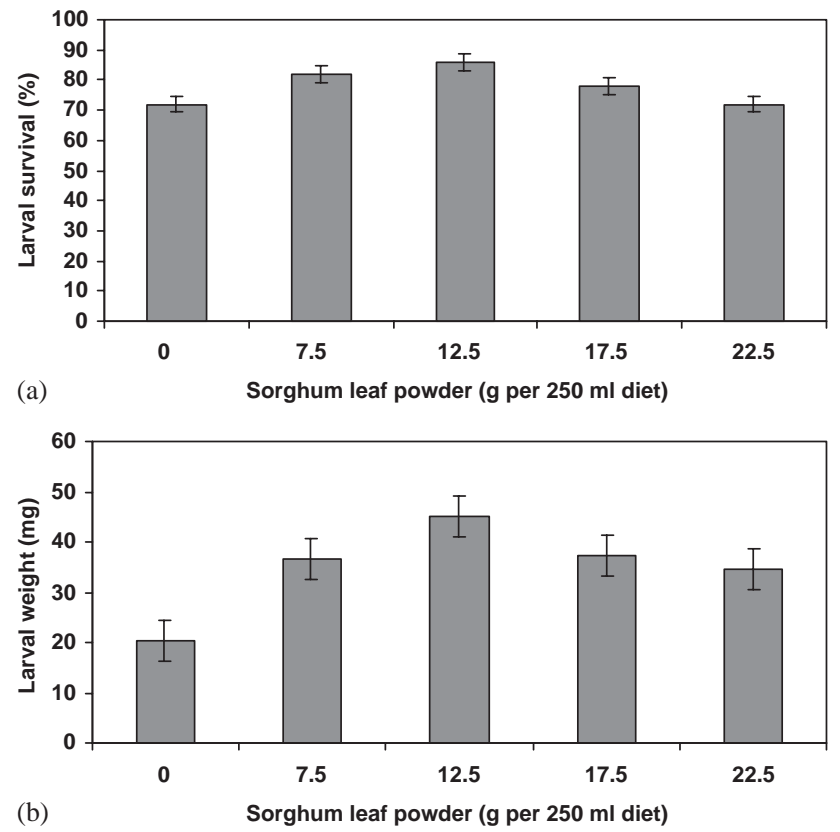

Fig. 1. Survival (Fig. 1a) and weight (Fig. 1b) of Chilo partellus larvae (mean \pm SE) at 10 days after inoculation on artificial diet impregnated with different amounts of CSH 1 leaf powder (ICRISAT, Patancheru, India). 
reared on diet having $12.5 \mathrm{~g}$ sorghum leaf powder per $250 \mathrm{ml}$ diet. The results suggested that $12.5 \mathrm{~g}$ sorghum leaf powder is optimum for larval development, while adverse effects of sorghum leaf powder were apparent at $22.5 \mathrm{~g}$ leaf powder per $250 \mathrm{ml}$ diet.

Larval survival and larval weight were significantly lower when the complete amount of chickpea flour in the artificial diet was substituted with sorghum leaf powder (Fig. 2). Larval survival ranged from $64.7 \%$ to $72.7 \%$ when the chickpea flower was substituted with leaf powder in different proportions. Mean larval survival in artificial diet with leaf powder of ICSV 743, ICSV 705 , and IS 5469 was $66.4 \%, 67.8 \%$, and $75.2 \%$, respectively. Maximum differences $(24 \%)$ in larval survival between the genotypes tested were observed at a 3:3 proportion of chickpea flour:sorghum leaf powder. Larval weight across genotypes ranged from 10 to $54 \mathrm{mg}$ at 10 days after inoculation. Larval weight was maximum in artificial diets having a $3: 3$ ratio of chickpea flour:sorghum leaf powder. Maximum differences in larval weight were observed in diets having 2:4 or 3:3 proportion of chickpea flour:sorghum leaf powder. Larval weight across different proportions of chickpea flour:sorghum leaf powder was $29 \mathrm{mg}$ on ICSV 705 and $34 \mathrm{mg}$ on ICSV 743 and IS 5469. Therefore, chickpea flour can be substituted by 50\% (3:3 proportion) with sorghum leaf powder to evaluate sorghum
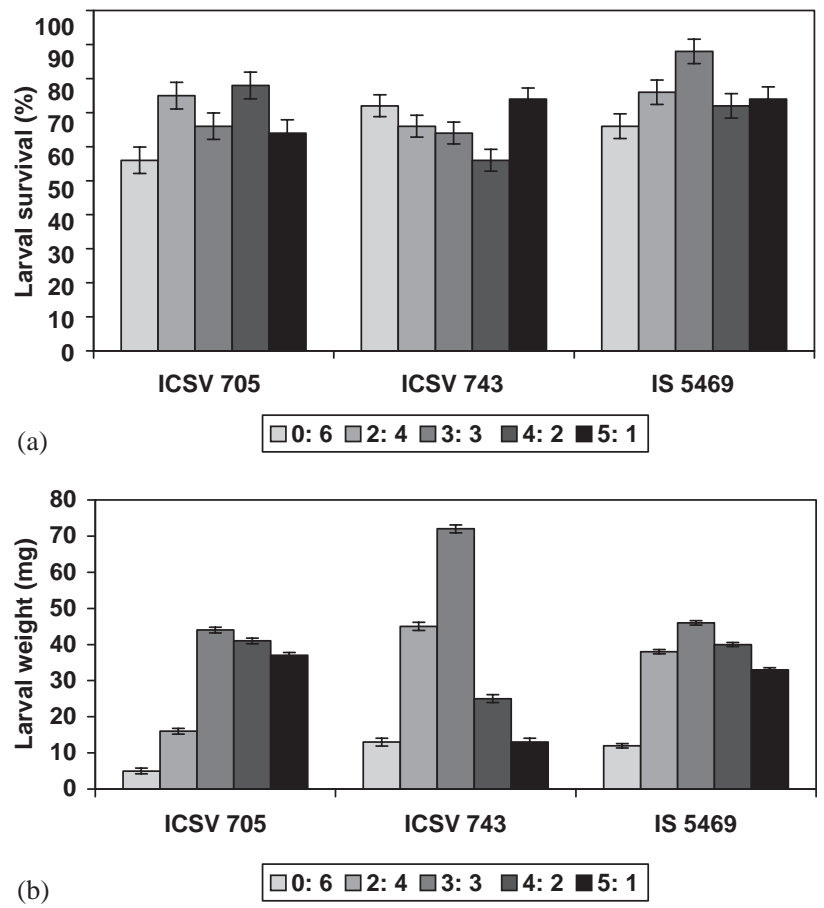

Fig. 2. Survival (Fig. 2a) and weight (Fig. 2b) of Chilo partellus larvae (mean \pm SE) at 10 days after inoculation on artificial diet with different proportions of chickpea flour:sorghum leaf powder (0:6, 2:4, 3:3, 4:2, and 5:1, respectively) of three sorghum genotypes (ICRISAT, Patancheru, India). genotypes for antibiosis component of resistance to $C$. partellus.

\subsection{Survival and development of C. partellus on artificial diet impregnated with lyophilized leaf powder of different sorghum genotypes}

Antibiosis component of resistance to $C$. partellus in 20 sorghum genotypes was studied in terms of survival and development on artificial diet impregnated with freeze-dried leaf powder of different sorghum genotypes. Data on larval survival, larval weight, duration of larval and pupal development, post-embryonic development period, pupal weight, and pupation and adult emergence were taken as a measure of antibiosis component of resistance to $C$. partellus. Larval survival and larval weight of $C$. partellus larvae reared on artificial diet impregnated with lyophilized leaf powder showed significant differences between the genotypes tested. Larval survival was $<70 \%$ in diets with freeze-dried leaf powder of IS 1044, IS 2269, IS 18573, IS 21444, and ICSV 714 compared to $>90 \%$ survival in artificial diet impregnated with leaf powder of AF 28, Seredo, and Naga White (Table 2). The larval weight was $<2.5 \mathrm{mg}$ on artificial diets with IS 1044, IS 1054, IS 2269, IS 5566, IS 18573, IS 21444, ICSV 705, and ICSV 714 leaf powder compared to $6.5-11.1 \mathrm{mg}$ on AF 28 , Seredo, and ICSV 1. Low larval survival and larval weight at $10 \mathrm{DAI}$ were recorded on IS 1044, IS 1054, IS 18573, IS 21444 , ICSV 705, and ICSV 714. Weight of the male pupae was significantly lower than that of the female pupae. Pupal weight varied from 46.0 to $72.5 \mathrm{mg}$ for the males and from 81.1 to $143.5 \mathrm{mg}$ for the females. Significantly lower pupal weight was observed in male and female pupae from the larvae reared on diets with leaf powder of IS 1044, IS 5566, IS 13100, IS 18573, and ICSV 705, and ICSV 714 as compared to those insects reared on IS 5604, IS 18333, Seredo, and ICSV 1.

Percentage pupation varied from $15 \%$ to $76 \%$, while the adult emergence varied from $10 \%$ to $40 \%$. Comparatively lower pupation $(<30 \%)$ and adult emergence $(<10 \%)$ were recorded in artificial diets impregnated with leaf powder of IS 2123, IS 2269, IS 5566, IS 18573, IS 21444, ICSV 705, and ICSV 714 as compared to those reared on diets with leaf powder of IS 5469, IS 5604, IS 12308, IS 13100, IS 18333, AF 28, and Seredo ( $>50 \%$ pupation and $>30 \%$ adult emergence). The larval period varied from 24.5 to 38.0 days for males, and from 23.3 to 39.0 days for the females on artificial diet impregnated with leaf powder from different sorghum genotypes (Table 3). Larval duration for the males was prolonged by 10 days on IS 1044, IS 2269, ICSV 705, and ICSV 714 as compared to that on IS 13100. Duration of larval period for the females was significantly longer on IS 1044, IS 2123, IS 5566, and ICSV 714 as compared to the larvae reared on AF 28. 
Pupal period was $>10$ days on IS 1054 , IS 5604, and Naga White for the males, and IS 5604, and Seredo for the females compared to 6.0 and 6.3 days for the males

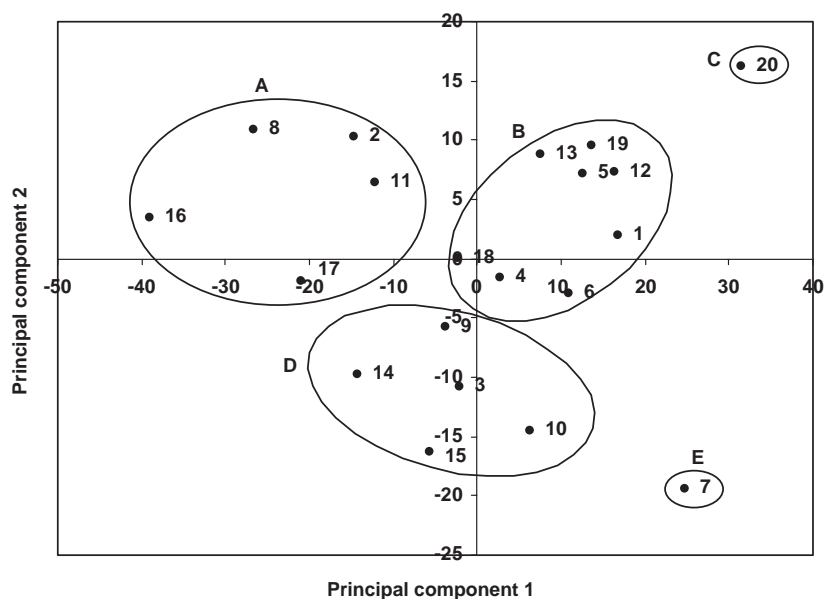

Fig. 3. Principal component analysis of 20 sorghum genotypes for diversity of resistance to Chilo partellus based on larval survival and development on artificial diet impregnated with freeze-dried leaf powder (ICRISAT, Patancheru, India). [1 = IS 1044, $2=$ IS 1054, $3=$ IS $2123,4=$ IS $2263,5=$ IS $2269,6=$ IS $5469,7=$ IS 5566 , $8=$ IS $5604,9=$ IS $12308,10=$ IS $13100,11=$ IS $18333,12=$ IS $18573,13=$ IS $21444,14=$ AF $28,15=$ Naga White, $16=$ Seredo, $17=\operatorname{ICSV} 1,18=\operatorname{ICSV} 112,19=\operatorname{ICSV} 705$, and $20=\operatorname{ICSV} 714]$. and females on AF 28, respectively. Post-embryonic development period for the males and/or females was prolonged by over 10 days when reared on diets with freeze-dried leaf powder of IS 1044, IS 2123, IS 2269, IS 5469, IS 18573, Naga White, ICSV 705, and ICSV 714.

Principal component analysis of the 20 genotypes tested (based on larval survival, larval and pupal weight, percentage pupation and adult emergence, and duration of post-embryonic development) indicated that there is considerable diversity in sorghum genotypes for antibiosis component of resistance to C. partellus (Fig. 3). The test genotypes were placed into five groups of (A) IS 1054, IS 5604, Seredo, IS 18333, and ICSV 1; (B) IS 1044, IS 2263, IS 2269, IS 5469, IS 18573, IS 21444, ICSV 705, and ICSV 112; (C) ICSV 714; (D) IS 2123, IS 12308, IS 13100, AF 28, and Naga White; and (E) IS 5566. The genotypes placed in different groups, and showing antibiosis to $C$. partellus can be used in resistance breeding programs to diversify the basis of resistance to this pest.

\section{Discussion}

Adverse effects of stem borer-resistant lines on survival and development of $C$. partellus under field

Table 2

Survival and development of spotted stem-borer, Chilo partellus larvae on artificial diet impregnated with leaf powder of different sorghum genotypes

\begin{tabular}{|c|c|c|c|c|c|c|}
\hline \multirow[t]{2}{*}{ Genotype } & \multirow{2}{*}{$\begin{array}{l}\text { Larval survival (\%) } \\
10 \text { DAI }\end{array}$} & \multirow{2}{*}{$\begin{array}{l}\text { Larval weight }(\mathrm{mg}) \\
10 \text { DAI }\end{array}$} & \multicolumn{2}{|c|}{ Pupal weight (mg) } & \multirow{2}{*}{$\begin{array}{l}\text { Pupation (\%) } \\
\text { Total }\end{array}$} & \multirow{2}{*}{$\begin{array}{l}\text { Adult emergence }(\%) \\
\text { Total }\end{array}$} \\
\hline & & & Males & Females & & \\
\hline IS 1044 & $70(56.9)^{*}$ & $0.8(1.1)^{* *}$ & 49.0 & 98.6 & 30.0 & 20.0 \\
\hline IS 1054 & $75(63.0)$ & $2.0(1.5)$ & 60.8 & 127.9 & 56.7 & 10.0 \\
\hline IS 2123 & $88(69.5)$ & $2.8(1.7)$ & 63.3 & 106.3 & 25.0 & 10.0 \\
\hline IS 2263 & $75(63.5)$ & $3.3(1.9)$ & 62.3 & 104.5 & 40.0 & 30.0 \\
\hline IS 2269 & $68(55.6)$ & $0.7(1.1)$ & 53.5 & - & 15.0 & 10.0 \\
\hline IS 5469 & 73 (58.6) & $2.6(1.7)$ & 62.4 & 96.8 & 53.3 & 30.0 \\
\hline IS 5566 & $85(67.3)$ & $1.0(1.2)$ & 51.4 & 81.1 & 30.0 & 10.0 \\
\hline IS 5604 & $78(62.2)$ & $4.3(2.1)$ & 65.2 & 136.9 & 50.0 & 26.7 \\
\hline IS 12308 & $82(67.8)$ & $4.4(2.2)$ & 61.7 & 108.9 & 55.0 & 40.0 \\
\hline IS 13100 & $86(73.0)$ & $4.6(2.2)$ & 50.6 & 98.0 & 60.0 & 33.3 \\
\hline IS 18333 & $74(59.6)$ & $4.1(2.1)$ & 69.5 & 120.1 & 76.7 & 33.3 \\
\hline IS 18573 & $65(53.9)$ & $1.3(1.3)$ & 46.0 & 101.7 & 20.0 & 10.0 \\
\hline IS 21444 & $65(54.4)$ & $1.8(1.5)$ & 56.5 & 107.0 & 30.0 & 10.0 \\
\hline AF 28 & $90(76.0)$ & $11.1(3.3)$ & 61.2 & 116.3 & 56.7 & 36.7 \\
\hline Naga White & $94(81.0)$ & $2.8(1.8)$ & 62.2 & 107.0 & 55.0 & 20.0 \\
\hline Seredo & $90(76.0)$ & $8.1(2.9)$ & 72.5 & 143.5 & 50.0 & 30.0 \\
\hline ICSV 705 & $65(54.6)$ & $0.5(1.0)$ & 52.8 & - & 20.0 & 10.0 \\
\hline ICSV 714 & $50(45.0)$ & $0.5(1.0)$ & 49.8 & 91.4 & 30.0 & 10.0 \\
\hline ICSV 1 & $86(73.1)$ & $6.5(2.6)$ & 67.8 & 125.0 & 55.0 & 20.0 \\
\hline ICSV 112 & $78(62.2)$ & $2.4(1.7)$ & 58.8 & 111.8 & 46.7 & 20.0 \\
\hline Mean & $76(63.4)$ & $2.9(1.7)$ & 58.8 & 104.6 & 34.2 & 16.8 \\
\hline $\mathrm{SE} \pm$ & 4.95 & 0.090 & 2.82 & 4.82 & 4.45 & 2.51 \\
\hline LSD at $5 \%$ & 13.72 & 0.25 & 8.01 & 13.68 & 12.65 & 5.04 \\
\hline
\end{tabular}

-Data not recorded due to fungal infection.

*Angular transformed values.

**Square root transformed values. 
Table 3

Duration of larval, pupal, and post-embryonic development (days) of spotted stem borer, Chilo partellus larvae on 25 sorghum genotypes (ICRISAT Center, Patancheru, 1999 rainy season).

\begin{tabular}{|c|c|c|c|c|c|c|}
\hline \multirow[t]{2}{*}{ Genotype } & \multicolumn{2}{|l|}{ Larvae } & \multicolumn{2}{|l|}{ Pupae } & \multicolumn{2}{|c|}{ Post-embryonic } \\
\hline & Males & Females & Males & Females & Males & Females \\
\hline IS 1044 & 35.1 & 34.0 & 7.0 & - & 42.1 & 38.0 \\
\hline IS 1054 & 28.6 & 30.7 & 10.0 & - & 38.6 & - \\
\hline IS 2123 & 31.5 & 34.3 & - & 8.0 & - & 42.3 \\
\hline IS 2263 & 27.5 & 28.0 & 8.5 & 8.0 & 36.0 & 36.0 \\
\hline IS 2269 & 38.0 & - & - & - & 43.0 & - \\
\hline IS 5469 & 29.8 & 32.4 & 8.0 & 8.0 & 37.8 & 40.4 \\
\hline IS 5566 & 33.0 & 38.5 & - & - & 38.0 & - \\
\hline IS 5604 & 25.5 & 24.6 & 10.0 & 10.3 & 35.5 & 34.9 \\
\hline IS 12308 & 26.3 & 27.6 & 7.8 & - & 34.0 & 31.6 \\
\hline IS 13100 & 24.5 & 24.1 & 6.7 & 8.9 & 30.2 & 33.0 \\
\hline IS 18333 & 27.4 & 28.0 & 7.8 & 8.7 & 35.0 & 36.7 \\
\hline IS 18573 & 31.0 & 33.0 & - & 8.0 & - & 41.0 \\
\hline IS 21444 & 28.7 & 30.7 & - & 7.5 & - & 38.2 \\
\hline AF 28 & 26.1 & 23.3 & 6.0 & 6.3 & 32.1 & 29.7 \\
\hline Naga White & 27.3 & 32.9 & 11.0 & 8.0 & 38.3 & 40.9 \\
\hline Seredo & 26.5 & 26.0 & 8.5 & 11.0 & 35.0 & 37.0 \\
\hline ICSV 705 & 37.0 & - & 9.0 & - & 46.0 & - \\
\hline ICSV 714 & 37.0 & 39.0 & 8.0 & - & 45.0 & - \\
\hline ICSV 1 & 25.3 & 27.1 & 9.0 & 8.0 & 34.3 & 35.1 \\
\hline ICSV 112 & 29.3 & 30.2 & 7.0 & 7.0 & 36.3 & 37.2 \\
\hline Mean & 29.8 & 30.2 & 8.3 & 8.3 & 37.5 & 37.8 \\
\hline $\mathrm{SE} \pm$ & 0.89 & 1.03 & 0.36 & 0.45 & 0.8 & 1.2 \\
\hline LSD at $5 \%$ & 2.53 & 2.93 & 1.01 & 1.28 & 2.29 & 3.26 \\
\hline
\end{tabular}

-Data not recorded due to fungal infection.

conditions have been reported by Lal and Pant (1980), Singh and Verma (1988), and Woodhead and Taneja (1987). However, expression of resistance to C. partellus under field conditions is quite variable due to variation in environmental conditions, differential growth of the test genotypes, and the nutrient status of the soil. Impregnation of freeze-dried leaf powder into the artificial diet is helpful to overcome the variation in borer infestation observed under field conditions to allow a comparison of the test genotypes under uniform conditions.

Freeze-dried sorghum leaf powder at $12.5 \mathrm{~g}$ per $250 \mathrm{ml}$ of the standard artificial diet (Sharma et al., 1992) can be used to quantify antibiosis component of resistance towards C. partellus. Alternatively, chickpea flour in the standard artificial diet can be substituted by $50 \%$ with the freeze-dried sorghum leaf powder to quantify the extent of antibiosis towards the larvae of $C$. partellus. There was a considerable variation in larval survival, larval and pupal weight, larval and pupal development period, and percentage pupation and adult emergence in diets impregnated with freeze-dried leaf powder of different sorghum genotypes. Low larval survival and larval weight were recorded in artificial diets impregnated with freeze-dried leaf powder of IS 1044, followed by IS 1054, IS 18573, and IS 21444 at 10 days after larval inoculation, while lower pupal weight was observed in larvae reared on IS 1044, IS 5566, IS 13100, IS 18573, and ICSV 705, and ICSV 714. Low pupation $(<30 \%)$ and adult emergence $(<10 \%)$ were also recorded in artificial diet impregnated with leaf powder of IS 2123, IS 2269, IS 5566, IS 18573, IS 21444 , ICSV 705, and ICSV 714, while total development period for the males and/or females was prolonged by over 10 days on IS 1044, IS 2123, IS 2269, IS 5469, IS 18573, Naga White, ICSV 705, and ICSV 714.

Genotypic differences in larval establishment in the field have been reported on different sorghum genotypes (Jotwani et al., 1978; Woodhead and Taneja, 1987; Singh and Rana, 1989; Berg van den and Westhuizen van der, 1997). Larval, pupal, and the total development period is also prolonged (Jotwani et al., 1978; Lal and Sukhani, 1979, 1982; Singh and Rana, 1984, 1989; Saxena, 1990, 1992; Verma et al., 1992). Antibiosis is also expressed in terms of reduced pupal weight (Lal and Sukhani, 1982; Singh and Rana, 1984; Singh and Verma, 1988; Verma, et al., 1992) and low pupation and adult emergence (Singh and Verma, 1988). The antibiotic effects of the resistant genotypes on the development of C. Partellus may be because of secondary plant substances in the leaves and/or poor nutritional quality of the food. Low sugar content (Swarup and Chaugale, 1962), and greater amounts of amino acids, tannins, total phenols, neutral detergent fiber (NDF), acid detergent fiber (ADF), and lignins (Khurana and Verma, 1982, 1983), and silica content (Narwal, 1973) are associated with resistance to $C$. partellus in sorghum. Larval mortality is greater in diet impregnated with petroleum ether extract of the borerresistant lines. Methanolic extracts from the susceptible line IS 18363 showed greater feeding stimulation than the extracts from the less susceptible cultivar, IS 2205. IS 18363 had greater phenolic and sugar contents than the less susceptible cultivar, IS 2205 (Torto et al., 1990). These biochemical constituents might influence the insect survival and development adversely. Reduced survival and establishment will reduce the insect population and the resultant crop damage. Prolongation of development period will also result in reduction of number of generations in a season/year. These effects of the resistant varieties will have a constant and cumulative effect on the stem borer population over seasons (Sharma, 1993), and can be utilized as an environmental friendly method to reduce the damage by this pest under subsistence farming conditions. Principal component analysis indicated that there is considerable diversity in sorghum genotypes for antibiosis component of resistance to $C$. partellus. Genotypes placed in different groups, and showing antibiosis to $C$. partellus, can be used in resistance breeding programs to diversify the basis of resistance to this pest. 


\section{Acknowledgments}

The authors are thankful to $\mathrm{K}$ V Hariprasad, B U Singh, S V N Chandra, J Raja Rao, and V V Rao for their help in these experiments.

\section{References}

Berg van den, J., Westhuizen van der, M.C., 1997. Chilo partellus (Lepidoptera: Pyralidae) moth and larval response to levels of antixenosis and antibiosis in sorghum inbred lines under laboratory conditions. Bull. Entomol. Res. 87, 541-545.

Chapman, R.F., Woodhead, S., Bernays, E.A., 1983. Survival and dispersal of young larvae of Chilo partellus (Swinhoe) (Lepidoptera: Pyralidae) in two cultivars of sorghum. Bull. Entomol. Res. $73,65-74$

Dabrowski, Z.T., Kidiavai, E.L., 1983. Resistance of some sorghum lines to the spotted stalk borer, Chilo partellus, under western Kenyan conditions. Insect Sci. Appl. 4, 119-126.

International Crops Research Institute for the Semi-Arid Tropics (ICRISAT), 1992. The Medium Term Plan. Part II. International Crops Research Institute for the Semi-Arid Tropics (ICRISAT), Patancheru 502 324, Andhra Pradesh, India.

Jotwani, M.G., 1978. Investigations on insect pests of sorghum and millets with special reference to host plant resistance. Final Technical Report (1972-1977). Research Bulletin of the Division of Entomology, Indian Agricultural Research Institute, New Delhi, India. $114 \mathrm{pp}$

Jotwani, M.G., Chaudhari, S., Singh, S.P., 1978. Mechanism of resistance to Chilo partellus (Swinhoe) in sorghum. Indian J. Entomol. 40, 273-276.

Khurana, A.D., Verma, A.N., 1982. Amino acid contents in sorghum plants, resistance/susceptible to stemborer and shootfly. Indian J. Entomol. 44, 184-188.

Khurana, A.D., Verma, A.N., 1983. Some biochemical plant characters in relation to susceptibility of sorghum to stemborer and shootfly. Indian J. Entomol. 45, 29-37.

Lal, G., Pant, J.C., 1980. Laboratory and field testing for resistance in maize and sorghum varieties to Chilo partellus (Swinhoe). Indian J. Entomol. 42, 606-610.

Lal, G., Sukhani, T.R., 1979. Development of sorghum stem borer Chilo partellus (Swinhoe) larvae on some resistant lines of sorghum. Bull. Entomol. 20, 67-70.

Lal, G., Sukhani, T.R., 1982. Antibiotic effects of some resistant lines of sorghum on post-larval development of Chilo partellus Swinhoe. Indian J. Agri. Sci. 52, 127-129.

Narwal, R.P., 1973. Silica bodies and resistance to infection in jowar (Sorghum vulgare Pers.). Agra University. J. Res. (Sci.) 22, 17-20.

Nwanze, K.F., 1997. Integrated management of stemborers of sorghum and pearl millet. Insect Sci. Appl. 17, 1-8.

Pradhan, S., 1971. Investigations on insect pests of sorghum and millets. Final Technical Report (1965-1970). Division of Entomology, Indian Agricultural Research Institute, New Delhi, India, $157 \mathrm{pp}$.

Saxena, K.N., 1990. Mechanisms of resistance/susceptibility of certain sorghum cultivars to the stem borer Chilo partellus: role of behaviour and development. Entomol. Exp. Appl. 55, 91-99.
Saxena, K.N., 1992. Larval development of Chilo partellus (Swinhoe) (Lepidoptera: Pyralidae) on artificial diet incorporating leaf tissues of sorghum lines in relation to their resistance or susceptibility. Appl. Entomol. Zool. 27, 325-330.

Sharma, H.C., 1993. Host plant resístanse to insects in sorghum and its role in integrated pest management. Crop Protection 12, $11-37$.

Sharma, H.C., Nwanze, K.F., 1997. Mechanisms of resistance to insects in sorghum and their usefulness in crop improvement. Information Bulletin No. 45. International Crops Research Institute for the Semi-Arid Tropics (ICRISAT), Patancheru, Andhra Pradesh, India, 56pp.

Sharma, H.C., Taneja, S.L., Leuschner, K., Nwanze, K.F., 1992. Techniques to screen sorghums for resistance to insect pests. Information Bulletin No. 32. International Crops Research Institute for the Semi-Arid Tropics, Patancheru, Andhra Pradesh, India, 48pp.

Sharma, H.C., Taneja, S.L., Kameshwara Nao, N., Prasada Rao, K.E., 2003. Evaluation of sorghum germplasm for resístance to insects. Information Bulletin No. 63. International Crops Research Institute for the Semi-Arid Tropics (ICRISAT), Patancheru 502 324, Andhra Pradesh, India, 184pp.

Singh, B.U., Rana, B.S., 1984. Influence of varietal resistance on oviposition and larval development of stalk-borer Chilo partellus Swinhoe and its relationship to field resistance in sorghum. Insect Sci. Appl. 5, 287-296.

Singh, B.U., Rana, B.S., 1989. Varietal resistance in sorghum to spotted stem borer, Chilo partellus (Swinhoe). Insect Sci. Appl. 10, $3-27$.

Singh, S.P., Verma, A.N., 1988. Antibiosis mechanism of resistance to stem borer, Chilo partellus (Swinhoe) in sorghum. Insect Sci. Appl. 9, 579-582.

Singh, S.R., Vedamoorthy, G., Thobbi, V.V., Jotwani, M.G., Young, W.R., Balan, J.S., Srivastava, K.P., Sandhu, G.S., Krishnananda, N., 1968. Resistance to stem borer, Chilo zonellus (Swinhoe) and stem fly, Atherigona varia soccata Rond. in the world sorghum collection in India. Mem. Entomol. Soc. India 7, 1-79.

Sithanantham, S., Subramaniam, T.R., 1975. Sex determination of pupae of sorghum stalk borer, Chilo zonellus (Swinhoe). Madras Agri. J. 62, 62-63.

Swarup, V., Chaugale, D.S., 1962. A preliminary study of resistance of stem borer, Chilo zonellus (Swinhoe) infestation in sorghum (Sorghum vulgare Pers.). Curr. Sci. 31, 163-164.

Taneja, S.L., Leuschner, K., 1985. Methods of rearing, infestation and evaluation for Chilo partellus resistance in sorghum. In: Proceedings of International Symposium on Sorghum Entomology July 15-21, 1984. Texas A and M University, College Station, Texas, USA. International Crops Research Institute for the Semi-Arid Tropics (ICRISAT), Patancheru, Andhra Pradesh, India, pp. $175-188$

Torto, B., Hassanali, A., Saxena, K.N., 1990. Chemical aspects of Chilo partellus feeding on certain sorghum cultivars. Insect Sci. Appl. 11, 649-655.

Verma, O.P., Bhanot, J.P., Verma, A.N., 1992. Development of Chilo partellus (Swinhoe) on pest resistant and susceptible sorghum cultivars. J. Insect Sci. 5, 181-182.

Woodhead, S., Taneja, S.L., 1987. The importance of the behaviour of young larvae in sorghum resistance to Chilo partellus. Entomol. Exp. Appl. 45, 47-54. 